\title{
Aspects of Universitarian Distance Teaching and Online Learning
}

\author{
Christoph Beierle • Gabriele Kern-Isberner
}

Published online: 16 May 2012

(C) Springer-Verlag 2012

\begin{abstract}
Already well before the arrival of the Internet and the world wide web, distance teaching universities were established in various countries. Using the ubiquitous availability of the WWW and advances in modern information and communication technologies, new and exciting online learning offerings like Udacity are now available. From a personal perspective, we discuss aspects of universitarian distance teaching and online learning and present thoughts about benefits the different learning forms may provide.
\end{abstract}

The recent launch of Udacity by Sebastian Thrun and colleagues has drawn much attention to the issue of online education and in particular to the question which role online education can play on the university level. In the following, we will distinguish and discuss different aspects of these issues from a personal perspective, influenced by, among other things, our research and teaching experiences at the FernUniversität in Hagen and at different traditional on-campus universities.

Oral lectures and classes have been the traditional mode of teaching right from the first universities, and they are still the predominant mode of teaching today. Distance teaching universities were established in the last century in various countries; in their teaching mode, oral lectures of traditional on-campus universities were substituted by written courses. With the arrival of the WWW and modern information and

\section{Beierle}

FernUniversität in Hagen, Hagen, Germany

e-mail: christoph.beierle@fernuni-hagen.de

G. Kern-Isberner $(\bowtie)$

TU Dortmund, Dortmund, Germany

e-mail: gabriele.kern-isberner@cs.uni-dortmund.de communication technologies, the mode of online education has offered new possibilities, like a rich mix of different media, instant delivery, and automated interactive formats. For instance, the FernUniversität in Hagen employs blended learning, a mix of these teaching modes, with all courses being available in written form, online education for homework assignments, or oral teaching scenarios in weekend seminars.

Presumably beyond dispute, learning is always a very personal affair. Without the activities of the learner plunging into and often struggling with the learning matter, without the final incorporation of new information into her knowledge, no learning process can be successful. This usually needs a lot of support in the form of technical explanations and didactic guidance, but also of motivation and feedback which brings the person of the teacher crucially into play. Providing continuous and direct personal support has been a successful basis for traditional universitarian teaching, and it still seems to be the most adequate way to foster advanced teaching that needs scientific discussions.

However, the availability of new media and the ubiquitousness of computers have not only changed the possibilities of remote teaching, they have also changed drastically the ways in which (not only young) people establish and maintain personal and social contacts. Be it for better or for worse, members of societies that use Wikipedia at least for a first source of information and spend a considerable part of their private life in virtual networks, will very probably expect corresponding forms of teaching material and also develop new forms of learning when working with these materials. These changes can not be overlooked even in oncampus universities. Online forums provide important platforms for exchanging informations, more and more students ask for videos of lectures, and the usually remarkable fraction of students sitting in lectures and paying more attention 
to their laptop computers or smartphones than to the teacher in front of them is infamous. This is not to say that we simply have to accept all this. Just to the contrary-it is our predominant task as teachers to provide and sometimes enforce an optimal frame for effective learning. But this also implies that we should deliberate about profits that learners (and sometimes also teachers) can take from any form of distance and online teaching.

Traditional face-to-face teaching requires teacher and student to be at the same place at the same time - and giving up these requirements is precisely the fundamental idea of distance teaching. At a distance teaching university, students can freely choose both the place where they want to study and also the time for studying. Especially distance teaching can profit from the online opportunities we have today, as also the furious start of Udacity shows.

Studying at a traditional on-campus university offers a wide variety of getting into fruitful contact with other students and with teachers, but also puts a lot of constraints on a student's life. There are many reasons why people might not be able to meet these requirements: They are employed and have to work, they care for their family, they are too young or too old, they have certain disabilities, due to special situations, they may not be able to leave the place where they live, they live in another country, etc. These people can be reached only or more effectively by distance teaching.

Some people agree that online education is possible, but negate that it is possible at the university level. Well, when the FernUniversität was founded in 1974, scepticism about universitarian level distance teaching was widely spread. Just as these sceptics were proven wrong, online teaching in computer science at the universitarian level is not only possible, but, at least in some places, already a reality. While this is true for specific online courses substituting traditional oral lectures, there are other forms of current education for which personal teacher feedback is mandatory. For instance, giving a talk to an audience and presenting general ideas and technical details is an essential ability for any graduate in computer science. A seminar where students present such talks can be organized via today's information and communication technologies, but it does require personal teacher feedback. The same holds when supervising a project or a B.Sc. or M.Sc. thesis.

Offering online education at a universitarian level has to be distinguished from getting a university degree based solely on online education. The difference surfaces especially when considering situations requiring direct studentteacher communication like in seminar talks, in supervising theses, or in oral examinations. All these situations can not be replaced by an online method with no teacher interaction, but they can be supported such that student and teacher still do not have to be at the same place. For instance, at the FernUniversität in Hagen, we have taken oral examinations as required in the regular study programs via videoconferencing, with our students being in USA, Japan, Australia, and many other parts of the world.

For a successfull university level education, direct student/student and student/teacher contacts seem to be essential. In distance teaching and online education such contacts do not arise as naturally as in traditional face-to-face teaching in on-campus universities. However, universities with a large number of students on the one hand and modern communication tools on the other hand have already changed this situation a bit. Students and teachers stay in contact via email, newsgroups, forums, etc. One of our students, who was studying also another subject at one of the largest oncampus universities in Germany, told us: "For me it is easier to get in direct contact with my professor at the FernUniversität than at my home university."

Many issues that we raised above would need a much deeper sociological and psychological discussion than we can provide. What we aimed to describe here are experiences both from traditional and online universitarian learning, and thoughts about benefits that each of the learning forms may provide. Just as we found personal feedback and weekend seminars forming an important part of distance teaching, online and offline materials may support and even enrich traditional universitarian teaching. Indeed, online material can support active learning in many, also personalised ways and foster more autonomous learning than traditional teaching methods usually do. It is up to us to take profit from combining both ways of teaching. 